\title{
A RELEVÂNCIA DO DESENVOLVIMENTO LOCAL PARA A PROMOÇÃO DO FLORESCIMENTO HUMANO NA DOENÇA DE ALZHEIMER (PORTUGAL)
}

JOANA CARRILHO DA SILVA ISCTE-Instituto Universitário de Lisboa joanacarrilhosilva@gmail.com

RESUMO: Em 2018, 1,88\% da população portuguesa foi diagnosticada com demência. Até 2050 prevê-se um aumento de pessoas com este diagnóstico para os 3,82\%, em grande medida, devido ao envelhecimento da população. O presente artigo visa mostrar como, em Portugal, existe a necessidade de criar soluções a partir de iniciativas de desenvolvimento local, para promover o bem-estar e qualidade de vida de pessoas com Alzheimer. Apresentamos uma análise comparada entre uma organização de ação nacional (Alzheimer Portugal) e uma clínica local privada (NeuroSer), por forma a compreender as dinâmicas relacionais que envolvem pessoas com Alzheimer (comunidade, profissionais de saúde, cuidadores informais/familiares) e o tipo de soluções que são apresentadas em Portugal.

Palavras-Chave: Demência; Bem-Estar; Qualidade de Vida; Florescimento Humano; Desenvolvimento Local. 
ABSTRACT: In 2018, 1.88\% of the Portuguese population was diagnosed with dementia. By 2050 this is expected to increase to $3.82 \%$, largely due to the ageing of the population. This article aims to show how, in Portugal, there is a need to create solutions through local development initiatives in order to promote the well-being and quality of life of people with Alzheimer's. We present a comparative analysis between a national action organization (Alzheimer Portugal) and a local private clinic (NeuroSer) in order to understand the relational dynamics involving people with Alzheimer's (community, health professionals, informal caregivers/ families) and the type of solutions that are presented in Portugal.

KeYwords: Dementia; Wellbeing; Quality of Life; Human Flourishing; Local Development. 


\section{Introdução'}

A Organização Mundial de Saúde (OMS, World Health Organization) estima que em todo o mundo existam cerca de 47.5 milhões de pessoas com demência (Alzheimer Portugal, 2017a), sendo a doença de Alzheimer (DA) a sua forma mais comum, representando entre $60 \%$ a $70 \%$ dos casos diagnosticados (WHO, 2017). Em termos de incidência em Portugal, estima-se que em 2018 existiriam 193516 pessoas diagnosticadas com demência (Alzheimer Europe, 2019: 12), representando 1.88\% da população ${ }^{2}$. Perante os dados apresentados, a OMS destaca que as demências deveriam ser consideradas como uma prioridade da saúde pública (The Lancet Neurology Commission, 2016:455). Esta premissa é reforçada pelo último estudo da Alzheimer Europe (2019: 96), onde a demência é referida como um dos principais desafios para os governos europeus. Neste ponto, surge a seguinte questão: serão os governos capazes de assegurar às pessoas, diagnosticadas com demência (nomeadamente Alzheimer), que os sistemas de saúde e apoio social providenciam cuidados de qualidade, garantindo o devido apoio até ao final da vida?3

Considerando que estamos perante uma doença crónica, e que o modelo médico vigente é focado na cura, na primeira secção procura compreender-se de que modo a DA é concebida pelos vários atores (doentes, cuidadores informais/familiares, terapeutas e profissionais de saúde) e, consequentemente, que dinâmicas são geradas (desde família até ao Estado) e de que forma a sua realidade é afetada (no seu quotidiano e a nível relacional) (primeiro objetivo específico). O caso da DA surge como uma chamada de atenção para a necessidade de mudança de paradigma médico, para um modelo que dê igual destaque a um tratamento paliativo

1 Este trabalho resulta da investigação de mestrado em Estudos de Desenvolvimento, conferido pela Universidade do ISCTE - Instituto Universitário de Lisboa, que apresentamos no "Congreso Internacional El cuidado de mayores y dependientes: avanzando hacia la igualdad de género y la justicia social.", nos dias 12 e 13 de setembro de 2019, na Universitat Rovira i Virgili.

2 Em termos de previsão de prevalência, os dados apontam para 229914 em 2025 (2.29\% da população) e 346905 em 2050 (3.82\% da população) (Ibidem:14-15).

3 Nesta linha, destaca-se a necessidade de as agendas de investigação priorizarem o tema da demência, nomeadamente os estudos demográficos, para melhor compreenderem a dimensão e realidade das populações que enfrentam esta realidade, permitindo a criação de melhores sistemas de resposta (Ibidem). 
(tratamento sintomatológico com enfoque na melhoria da qualidade de vida), valorizando a circunstância específica e historial da pessoa.

Neste sentido, enquanto doença crónica irreversível, o Alzheimer exige a ponderação do desenvolvimento de vetores como o "florescimento humano" (FH) (human flourishing) e a "qualidade de vida" (QdV) (tópicos desenvolvidos na segunda seção) para que exista uma avaliação do bem- estar (BE) da pessoa (mental, emocional e social), para além da satisfação das suas necessidades básicas. Para tal, será indispensável considerar a pessoa não só nos seus processos individuais, mas também, o seu envolvimento com a comunidade (que poderá trazer elementos positivos ao desenvolvimento pessoal e, consequentemente, a um estado de $\mathrm{FH}$ ). ${ }^{4}$ Desta forma, surge o segundo objetivo específico: entender o que é considerado como bem-estar e qualidade de vida, e também, de que forma estes poderiam ser alcançados.

Considerando os dados supracitados relativamente ao crescente número de diagnósticos de demência em Portugal ${ }^{5}$ (passando de 1,88\% da população em 2018 para 3,82\% em 2050) importa compreender se no país existem respostas suficientes, que acompanhem este crescimento. Neste sentido, o objetivo principal do presente estudo passa por compreender se o desenvolvimento local (DL) poderá ser um ponto de partida para a melhoria do BE e QdV para pessoas com Alzheimer, e outros tipos de demência, em Portugal. Para ser possível promover cada vez mais iniciativas de DL, torna-se necessária uma posição mais central por parte do Estado na construção de novas formas de regulação social (Henriques, 2007). Na transformação político-económica contemporânea, em que se acentuam os processos de globalização e, simultaneamente, de localização, importaria que os Estados desempenhassem uma função de "moderadores", criando as condições necessárias ao desenvolvimento de ações conjuntas entre os vários setores e, inclusive, uma ação da comunidade

4 Corey Keyes (2007) defende que esta mudança, em relação à forma como se perceciona a doença, para uma "consciência positiva" na sociedade, poderá ser alcançada através de programas nacionais, com estratégias focadas tanto na promoção da saúde mental, como na prevenção e tratamento da doença mental.

5 De acordo com os dados supracitados, em 2018 foram diagnosticados 193516 casos de demência, em Portugal, sendo que a previsão de prevalência aponta para os 346905 casos diagnosticados em 2050 (passando de 1,88\% da população para 3,82\%). 
local concertada numa união multinível. No decorrer da reflexão sobre as novas formas de governança multinível constatamos o surgimento, como possível solução, das redes sociais ${ }^{6}$.

Perante os objetivos e a questão de partida, colocam-se as seguintes hipóteses relativamente ao envolvimento da comunidade: (a) poderá constituir uma solução para as famílias que não têm apoios formais adequados, permitindo um apoio no próprio lar; (b) poderá ser insustentável, uma vez que se apresentam diversas variantes subjetivas (falta de meios para dar formação, falta de financiamento, falta de aceitação e envolvimento da comunidade, etc.); e, por fim, (c) considerando que cada comunidade apresenta características específicas, não se poderá chegar a uma única conclusão. Querendo com isto afirmar que, em determinadas comunidades, poderá concluir-se que não existem componentes suficientes que tornem esta possibilidade (de comunidades interventivas) sustentável - onde não seja possível criar uma rede informal de apoio a pessoas com Alzheimer, e outros tipos de demência.

\section{Metodologia e definição do perfil social}

Foram analisadas dinâmicas relacionais entre os vários atores (formais, informais e familiares) e o alcance da ação em dois casos distintos, com enfoque no cuidado da pessoa com DA (um cuidado especializado, focado no bem-estar da pessoa): numa Instituição Particular de Solidariedade Social (IPSS) com uma ação nacional —a Associação Alzheimer Portugal7 - e numa clínica privada com uma ação a nível local, em Lisboa -Clínica NeuroSer ${ }^{8}$ - para comparar o tipo de soluções que existiam entre estes atores (IPSS/clínica privada; ação nacional/ação local). Aplicou-se uma metodologia qualitativa, de tipologia explicativa-exploratória, através de técnicas de investigação qualitativas —observação participante (na iniciativa Café da Memória) e entrevistas (semiestruturadas

\footnotetext{
6 Forma de governação colaborativa e multinível.

7 Confira: $<$ http://alzheimerportugal.org/pt/>.

8 Confira: <http://neuroser.pt/>.
} 
e abertas, a nove pessoas, entre cuidadores familiares ${ }^{9}$ e profissionais de saúde).

O problema apresentado foi abordado através de uma investigação qualitativa, tomando como base uma metodologia explicativa-exploratória $^{10}$ (considerando o objetivo geral —de que modo o DL poderá, ou não, constituir um acréscimo positivo nas dinâmicas relacionais e redes formais já existente, promovendo a melhoria de BE e QdV da pessoa com DA e dos seus familiares). É feita uma fusão entre uma metodologia explicativa ${ }^{11}$, que pretende compreender o fenómeno nas dinâmicas criadas entre atores formais, familiares e pessoas com Alzheimer, e exploratória uma vez que se irá investigar uma possível solução de apoio - a hipótese do desenvolvimento de um plano flexível, aplicável ao local, que leve à criação de uma nova forma de intervenção.

O modelo conceptual, fundamentado numa análise bibliográfica ${ }^{12}$, permitiu criar uma coerência entre teoria e empiria, construindo uma base para as dimensões de análise e para contextualizar as entrevistas semiestruturadas e observação participante. Deste trabalho inicial, resultaram três conceitos chave, cada um associado a um objetivo: (a) Demência - (a.1.) Compreender de que forma os vários atores (pessoas com DA; cuidadores familiares (CF); familiares, amigos e/ou vizinhos; profissionais de saúde e Estado) concebem a DA (o que esta representa) (a.2.) Consequentemente, de que forma a sua realidade é afetada (no seu quotidiano e a nível relacional) - dinâmicas geradas (desde a família até ao Estado);

\footnotetext{
9 A designação mais utilizada é a de "cuidador informal". No entanto, na presente investigação, os três entrevistados são filhos e foi considerada uma utilização referida pelo Neurologista Alexandre Castro Caldas, que refere: "Um cuidador informal é um familiar, uma pessoa que tem uma relação de afeto com o outro" e que, por este motivo, considera mais adequada a designação de "cuidador familiar". No contexto da investigação, fez sentido utilizar uma designação menos distante.

10 "O modelo conceptual esboçado a partir dos primeiros contactos com o terreno e baseado na revisão bibliográfica tradicional seja entendido como a 'representação hipotética do que se pensa existir na realidade', isto é, como um modelo explicativo potencial. (...) Estamos num quadro de análise de 'processos' e de 'dinâmicas', pretendendo-se não apenas uma mera descrição da realidade, mas também a interpretação do sentido das dinâmicas sociais” (Guerra, 2006: 39).

11 Inclusive, Isabel Guerra (2006: 38) sublinha que, sendo exploratória, "a pesquisa termina com a elaboração de um modelo explicativo da realidade estudada", denominada por Bertaux (1997) de "hipóteses explicativas".

12 “(...) são as leituras feitas pelo investigador que concorrem para gerar a problemática” (Burguess, 1997 [1984]: 34).
} 
(b) Florescimento Humano - Compreender a conceptualização de BE e qualidade de vida, por parte das pessoas com DA e dos seus cuidadores e, consequentemente, de que forma se poderão otimizar as dinâmicas relacionais, potenciando assim o FH; (c) Desenvolvimento Local - Verificar se o DL (portanto, o envolvimento da comunidade) poderá constituir, como interrogamos anteriormente, um ponto de partida para a melhoria de $\mathrm{BE}$ e QdV das pessoas com DA (e outros tipos de demência), em Portugal. ${ }^{13}$

Para trabalho de campo foram considerados três locais que desenvolvem respostas para o cuidado de pessoas com DA: Centros de Dia da Alzheimer Portugal; Casa do Alecrim e Café de Memória. ${ }^{14}$ No entanto, após uma primeira reunião com a Alzheimer Portugal, ficou claro que não seria possível realizar a observação participante no Centro de Dia e na Casa do Alecrim, tendo em vista a necessária proteção dos utentes. Isto porque, no contexto desta doença, as quebras de rotina, como a presença de pessoas estranhas ao seu contexto diário, podem causar desconforto ou sobressalto. Para salvaguardar o melhor interesse de quem usufrui destes espaços, procurou-se colmatar a falta de recolha de informação neste contexto ${ }^{15}$ através de uma entrevista com a Diretora Técnica do Lar. Esta limitação, ao que deveria ter sido uma observação participante mais aprofundada nestes contextos, teve de ser superada, aumentando o número de entrevistas. Por conseguinte, o trabalho de campo foi realizado no Café da Memória de Almada (distrito de Lisboa), tendo sido observadas quatro sessões de duas horas cada. O Café da Memória ${ }^{16}$ é um espaço de partilha e apoio para cuidadores ou pessoas que sofram de perda de memória ou demência, havendo também um espaço de aprendizagem sobre a doença e sobre como lidar/cuidar melhor da pessoa, uma vez que

13 Silva (2018) - guiões utilizados em entrevista em anexo.

14 Considerando que a observação participante possibilita que o investigador estabeleça uma relação de proximidade com os indivíduos que se enquadram no contexto a ser analisado, permitindo encontrar linhas entre o conhecimento científico e a convivência quotidiana da realidade a ser observada.

15 “(...) o projeto e a metodologia da investigação estão a ser continuamente definidos e redefinidos pelo investigador e, nalguns casos, pelos próprios investigados. Nestes termos, os investigadores têm de ajustar constantemente as atividades nas quais estão envolvidos" (Burgess, 1997: 33).

16 "Os CAFÉS MEMÓRIA resultam de uma iniciativa de duas entidades promotoras, a Associação Alzheimer Portugal e a empresa Sonae Sierra e de um conjunto alargado de parceiros, e arrancou como projeto-piloto em Abril de 2013, com a abertura dos Cafés Memória de Lisboa-Colombo e de Cascais" (https://www.cafememoria.pt/quem-somos). 
em cada sessão um convidado fala sobre um tema diferente (como, por exemplo, a alimentação, a comunicação, o exercício, etc.). A atividade realiza-se uma vez por mês, num sábado à escolha (do grupo de voluntários local que a dinamiza), o que permite a presença de cuidadores a tempo inteiro. ${ }^{17}$

Para a definição das entrevistas individuais semiestruturadas ${ }^{18}$, foram consideradas um conjunto de variantes na definição do perfil e do número de entrevistas ${ }^{19}$ necessárias, a partir da teorização de Isabel Guerra (2006: 47), nomeadamente: tratando-se de uma aproximação inicial (estádio de conhecimento do objeto), esta é uma pesquisa explicativa-exploratória (estatuto da pesquisa), auscultando os atores que fazem parte das dinâmicas a serem estudadas, portanto, que lidem com a DA (tipo de definição do universo de análise). $\mathrm{O}$ universo de análise foi delimitado à ação na Grande Lisboa (Lisboa e Almada), por questões de logística e proximidade (tendo sido referido o número de respostas dado pela Alzheimer Portugal, enquanto instituição nacional de referência neste tema). O número de entrevistas aumentou de seis para dez, para permitir aprofundar diferentes áreas de especialização e diferentes pontos de vista. Começamos por criar três grupos distintos: (3) cuidadores familiares (CF), (3) terapeutas/ profissionais de saúde (terapeutas ocupacionais (TO) e/ou fisioterapeutas) e (4) especialistas (neurologistas, psiquiatras, membros de direção das instituições a serem analisadas). Surgiram limitações relativamente à possibilidade de entrevistar um psiquiatra na área da Grande Lisboa, por ausência de resposta ou de disponibilidade. ${ }^{20}$ Perante este cenário, colocou-se a possibilidade de entrevistar uma profissional da área da

17 Para realizar a recolha de dados, a autorização por parte da organização foi conseguida atempadamente. A iniciativa tem vindo a crescer, tendo sidos criadas várias iniciativas do Café da Memória ao longo do país — de momento existem 20 locais (incluindo a Região Autónoma da Madeira). Para mais informação sobre o projeto, consultar: <https://www.cafememoria.pt/>.

18 Constituem-se como um método intimista que traz um olhar mais aprofundado sobre o contexto do indivíduo (e sobre as dinâmicas geradas em torno do mesmo) - constitui-se como uma aplicação dos processos fundamentais $e$ da interação humana, através de uma troca entre entrevistado e investigador, permitindo a recolha de informação em profundidade (Quivy e Campenhoudt, 1995:191-192).

19 Consultar Silva, 2018, Capítulo 5 - Caracterização das Instituições e dos Perfis dos entrevistados (p. 77-83).

20 Nesse sentido, não foi possível comparar visões de duas áreas da medicina: neurologia e psiquiatra. 
Neuropsicologia, o que acrescentou uma visão fundamental para compreender o trabalho de uma equipa multidisciplinar (neste caso, da clínica NeuroSer) no acompanhamento de pessoas com DA.

A escolha dos estudos de caso (supracitada) pretende comparar dois tipos de resposta na zona da Grande Lisboa. Por um lado, uma Instituição Particular de Solidariedade Social (Associação Portuguesa de Familiares e Amigos de Doentes de Alzheimer (APFADA), sendo Alzheimer Portugal o nome pelo qual é mais conhecida), que providencia soluções como a Casa do Alecrim (situada no Estoril, que, por sua vez dispõe de três serviços distintos como o lar, o centro de dia e o apoio domiciliário), que possibilita apoio a 101 pessoas (cerca de 200 no total entre familiares e utentes); e o Centro de Dia Professor Doutor Carlos Garcia ${ }^{21}$ (Lisboa) que tem capacidade para receber 15 utentes em fase inicial ou moderada (sendo, preferencialmente, de freguesias circundantes ${ }^{22}$, tendo também disponível apoio domiciliário para 40 pessoas. ${ }^{23}$ Por outro lado, uma clínica privada, a clínica NeuroSer ${ }^{24}$ (situada em Telheiras), que tem uma ação mais local, promove, inclusive, atividades abertas à comunidade local (atividades no jardim, passeios, idas à mercearia local, entre outras atividades). A ação da clínica começa com uma avaliação que será construída em conjunto com o utente e os familiares, feita por uma equipa multidisciplinar, a partir das necessidades da pessoa com Alzheimer. É criado um plano de intervenção único, focado na pessoa e na sua história. ${ }^{25}$

21 Para mais informação sobre o Centro de Dia, consultar: <https://alzheimerportugal.org/pt/text-0-10-54-88-centro-de-dia-prof-doutor-carlos-garcia>.

22 Para mais informação sobre a Casa do Alecrim, consultar: <https://alzheimerportugal.org/pt/text-0-10-54-87-lar-e-centro-de-dia-casa-do-alecrim>.

23 Para além dos serviços apresentados, foi feito um levantamento de todos os serviços disponíveis e projetos da Alzheimer Portugal, não só na zona da Grande Lisboa, mas também em todo Portugal Continental e Ilhas (Silva, 2018: 80).

24 Relativamente aos serviços, existem duas modalidades: sessões individuais [...] e as sessões de grupo, realizadas nas manhãs e tardes do NeuroSer \{...] durante um período de $4 \mathrm{~h}$ ou $8 \mathrm{~h}$, onde se realizam atividades que procurem a estimulação em grupo [...]. E, por fim, existe uma parceria com a Re-food onde os seus utentes acabam por participar, cozinhando refeições que serão posteriormente entregues a famílias carenciadas. Esta criação de atividades centradas nas capacidades e necessidades da pessoa traz benefícios para o doente - que recebe um cuidado mais especializado, tendo também a possibilidade em manter a componente social na sua vida - e para os cuidadores familiares-que podem descansar e realizar a sua vida quotidiana. (Silva, 2018: 80-81).

25 «Este plano é reavaliado periodicamente com base na progressão da doença e do estado do doente, adaptando os planos de intervenção com regularidade» (Silva, 2018: 80). 
A definição do perfil social considerou cuidadores familiares (CF) que frequentavam o Café da Memória, com enfoque em perfis diferentes, no que diz respeito à forma escolhida para cuidar da mãe (pessoa com Alzheimer). Deste modo, a mãe da CF1 ainda mantinha a sua independência ${ }^{26}$; no caso do CF2, houve um contacto com a Santa Casa da Misericórdia para que a mãe pudesse ficar a ser cuidada num dos seus lares; no caso da CF3 a mãe mora consigo, sendo cuidadora a tempo inteiro. Relativamente aos profissionais de saúde, foram considerados aqueles que lidam com este quadro clínico, nos dois estudos de caso, considerando também diferentes tipos de experiência e área profissional (para uma visão multidisciplinar sobre o cuidado de pessoas com Alzheimer): (a) Alzheimer Portugal - psicóloga e diretora do gabinete de formação; terapeuta ocupacional; diretora técnica da casa do Alecrim; (b) NeuroSer - neurologista (e diretor clínico da Clínica NeuroSer), neuropsicóloga, terapeuta ocupacional e fisioterapeuta. ${ }^{27}$

\section{3. (Com)viver com a deterioração do ser - a doença de Alzheimer em Portugal}

A DA apresenta-se como a forma mais conhecida de demência, sendo por isso o foco da investigação. Enquanto doença neurodegenerativa, é reconhecida pelas Nações Unidas como «Doença Crónica Não-Transmissível» (Alzheimer Portugal, 2017a). É uma síndrome degenerativa, de natureza crónica ou progressiva, que leva à deterioração das funções cognitivas (memória e raciocínio lógico), afetando também o comportamento e a autonomia no desempenho de tarefas básicas do quotidiano (comer, vestir, entre outras) (OMS, 2017). A demência tem impacto a nível individual (psicológico e físico), social e económico, não só do doente, mas também do(s) seu(s) cuidador(es), nas famílias e na comunidade local. Pelos motivos apresentados, esta doença representa uma das maiores causas, a

26 Com o apoio de um tio, a cuidadora fazia visitas regulares, principalmente nas horas de refeição. 27 Foi apresentado aos entrevistados um Modelo de Autorização da Entrevista onde os entrevistados autorizavam a gravação da entrevista, tendo sido acordado com todos os profissionais de saúde a citação mediante aprovação prévia. 
nível global, de desabilidade e falta de autonomia na comunidade mais envelhecida.

O envelhecimento em Portugal tem vindo a aumentar nos últimos anos (INE, 2017) e em 2018 estima-se que $1.88 \%$ da população tenha sido diagnosticada com demência (Alzheimer Europe, 2019: 12), o que faz da demência uma preocupação de âmbito nacional. Desta forma, colocam-se as seguintes questões: existem respostas suficientes, adequadas, às suas necessidades (das pessoas com demência)? As soluções encontradas até ao momento (lares e centros de dia) têm tido cuidados que vão para além da satisfação das suas necessidades básicas (alimentação, higiene, abrigo) e que procuram criar bem-estar na pessoa? O Jornal de Negócios ${ }^{28}$ noticia que em março de 2018 :

operavam em Portugal cerca de 2.500 residências para a terceira idade [...] o total de residências ativas rondava os 98.100 lugares, com uma capacidade média de 40 lugares por centro, sendo que $78 \%$ do número total de lugares (76.308) correspondia a entidades gestoras de centros não lucrativos, situando-se a capacidade das residências lucrativas em cerca de 21.800 lugares (Neves, 2019, Jornal de Negócios).

Analisando os números, comecemos por considerar que a idade é o principal fator de risco e que a partir dos 65 anos começa a aumentar o risco de desenvolver DA e outros tipos de demência. Em 2018, Portugal tinha cerca de 2244225 pessoas com mais de 65 anos, sendo que, destas, 310274 teriam idade igual ou superior a 85 anos (INE, 2019). Claro que uma grande parte conseguirá levar o seu dia a dia de forma independente. Mas, consideremos os valores apresentados para 2018 (supracitados), que nos dizem que foram diagnosticadas cerca de 193516 pessoas com demência, deste número, mesmo que não recorram todos a lares e a centros de dia no momento, a demência tende a trazer limitações gradualmente, o que levará a uma procura de apoio por parte dos cuidadores - alguns terão de institucionalizar os seus familiares, outros conseguirão cuidar em casa, com apoio domiciliário. Mas não são só os casos de demência que procuram este tipo de serviços e apoios (lares e centros de dia, seja

28 Disponível em: <https://www.jornaldenegocios.pt/economia/detalhe/negocio-dos-lares-para-idosos-ja-vale-mais-de-300-milhoes-em-portugal>. Acedido a: [24 de outubro de 2020]. 
por necessidade, por falta de resposta em termos familiares ou por outros diagnósticos). Em Portugal (2018) estavam a operar residências que disponibilizavam 98100 lugares (cerca de 40 lugares por instituição). Se olharmos apenas para os números das pessoas diagnosticadas com demência, e considerarmos que, em fases mais avançadas, o cenário mais comum é que as famílias procurem sítios que as possam acolher, garantindo um cuidado adequado durante $24 \mathrm{~h}$, o número de respostas é claramente insuficiente. Parte do problema, identificado pelos entrevistados, encontra-se na limitação de recursos do Sistema Nacional de Saúde (SNS) português e na ausência de um Plano Nacional de Demências (PND), que permita um maior apoio no desenvolvimento de respostas adequadas, em termos de quantidade e de um cuidado com qualidade.

Numa avaliação feita pelo Instituto de Segurança Social, I.P. (2005), em parceria com a Alzheimer Portugal, em 2005, questionaram-se familiares de pessoas com Alzheimer sobre as suas principais necessidades. Neste ponto, destacaram-se os serviços de saúde, nomeadamente: os cuidados de terapia de reabilitação e o acesso a consultas de especialidade (Neurologia e Psiquiatria) e "um sentimento global de insuficiência relativamente ao acesso aos apoios sociais, onde se revelaram as maiores necessidades de respostas" ou seja, consideram que existe uma "total desadequação das estruturas existentes (lares, centros de dia e serviços de apoio domiciliário) face às particularidades da doença de Alzheimer" (Instituto de Segurança Social, I.P., 2005: 35). Considerando estes dados, surge assim a questão de partida e o objetivo principal desta investigação (previamente enunciado): poderá o desenvolvimento local contribuir para o bem-estar e qualidade de vida em pessoas com doença de Alzheimer?

Para trabalharmos sobre o objetivo principal proposto, mostrou-se relevante começar por compreender a demência e a conceção dos atores que lidam com esta realidade. Desta forma, tem-se como um dos objetivos específicos compreender de que modo a DA é concebida pelos vários atores (pessoas com Alzheimer, cuidadores familiares, terapeutas e profissionais de saúde) e de que forma é que esta vivência afeta a sua realidade (no seu quotidiano e a nível relacional). Para tal, foram identificadas as seguintes dimensões de análise: fatores internos (idade, quadro clínico e 
genética), fatores externos (hábitos e estilo de vida; a perda de alguém próximo; a educação, que irá influenciar a forma como se lida com o diagnóstico), estigma —-"existe ou não?", se existe, de que forma se reflete na convivência com esta realidade (por parte da comunidade, de amigos próximos, família, e até nos profissionais de saúde)?

\subsection{A doença de Alzheimer e os fatores de risco}

Enquanto doença neurodegenerativa ${ }^{29}$, existe um tempo considerável entre o início da degradação celular, causado pela presença de placas neuríticas (placas senis - que surgem por acumulações extracelulares de proteína beta-amilóide $(A \beta)$ ) e de novelos neurofibrilares ${ }^{30}$, e a manifestação de sintomas que interfiram diretamente com o normal funcionamento do dia-a-dia, nomeadamente, quando começam a existir sinais de desgaste ou limitação física. Existe uma concordância académica na medicina, segundo a qual são identificadas três fases de progressão: ligeira (inicial), moderada e severa (avançada), sendo que na grande maioria dos casos, não é possível um diagnóstico conclusivo na fase inicial ${ }^{31}$. Nesta fase os sintomas manifestam-se subtilmente, o que leva à sua desvalorização, num grande número de vezes e, consequentemente, a diagnósticos errados de "depressão" ou de uma "sintomatologia própria do avanço da idade"32. A degradação progressiva leva a um sentimento de perda por

\footnotetext{
29 Para mais desenvolvimentos confira: Classificação Internacional das Doenças (CID-10) da Organização Mundial de Saúde (OMS); o Manual de Diagnóstico e Estatística das Perturbações Mentais (DSM-IV) da Associação Americana de Psiquiatria (AAP); NINCDS - National Institute of Neurological and Communicative Disorders Stroke [online: <https://www.ninds.nih.gov/]>; ADRDA: Alzheimer's Disease and Related Disorders Association.

30 «Wavy filaments of neural tissue characteristic of A.D» (Belsky, 1999: 2-3).

31 "Geralmente, as características da Demência são classificadas em três etapas ou fases. É importante salientar que algumas pessoas não apresentam todas as características ou passam por todas as fases. De qualquer forma, esta continua a ser uma descrição útil da progressão geral da demência" (Alzheimer Portugal, 2017b).

32 A pessoa começa por ter a perceção de algumas limitações (designadamente, quando a degradação cognitiva interfere no normal funcionamento das atividades da vida diária - desorientação temporal e espacial) e, mais tarde, essa perceção é tida pelos familiares. Por norma, o tratamento adequado deverá iniciar-se por neurologistas e psiquiatras.
} 
parte dos familiares, partilhada pelos cuidadores entrevistados: «-Esta não é a mãe que eu tinha» ${ }^{33}$.

A idade é o principal fator de risco, sendo mais comum a partir dos 65 anos. Os cuidadores entrevistados tinham as suas mães diagnosticadas com demência (Alzheimer em dois dos casos) tendo idades entre os 71 e os 80 anos de idade. A saúde da pessoa - o seu quadro clínico - também é fundamental (AVC's, problemas de coração, etc.). Por fim, importa igualmente o fator genético ${ }^{34}$, sendo que existe uma forma familiar da doença que é transmitida, representando apenas $2 \%$ dos casos (Pinho, 2008: 14). Sendo a causa da DA desconhecida, o trabalho de investigação realizado sobre o que pode influenciar o seu desenvolvimento tem sido extenso, sem ser ainda possível fazer uma ligação direta entre "causa" e "efeito". No entanto, o mais recente estudo relacionado com a importância dos fatores externos, publicado pela Comissão de Neurologia The Lancet (2017), apresenta nove fatores de risco (evitáveis) que têm uma influência em, aproximadamente, um terço dos casos a nível mundial (35\% dos casos), sendo eles: perda de audição na meia idade ( $9 \%)$; não inclusão no ensino médio (8\%); consumo de tabaco (5\%); depressão (4\%); sedentarismo (3\%); isolamento social (2\%); obesidade (1\%); diabetes tipo II (2\%) ${ }^{35}$. A partir dos dados apresentados, podemos destacar a importância de terapias não

$33 \mathrm{~A}$ forma como cada cuidador familiar lida com o diagnóstico dependerá de um conjunto de fatores ligados à sua história pessoal. Há cuidadores que preferem não pesquisar informação como forma de se proteger (cuidador familiar (CF) 3 - tendo ainda o doente a morar consigo); cuidadores que procuram informação dando apoio em casa (porque o estado da doença ainda o permite - CF1) ou, ainda, cuidadores que recorrem à ajuda de uma instituição para proceder ao diagnóstico e apoio adequado providenciado pela mesma (CF2).

34 Esta forma de Alzheimer está «[...] relacionada com a transmissão hereditária autossómica dominante de mutações de genes envolvidos na produção e no metabolismo de proteínas amilóides, nomeadamente, o gene da proteína precursora da proteína beta-amilóide (cromossoma 21), o gene da pré-senilina 1 (cromossoma 14) e o gene da pré-senilina 2 (cromossoma 1)» (Pinho, 2008: 14). Relativamente à origem da demência de Alzheimer tardia ainda prevalece um desentendimento, existindo duas teorias «uma que sugere como principal factor patogénico a acumulação de proteína beta-amilóide e outra que defende a hipoperfusão cerebral como principal mecanismo de degenerescência neuronal» (Ibidem).

$35 \mathrm{O}$ estudo apresenta um modelo populacional, não podendo ser aplicado a nível individual - querendo com isto dizer que os valores apresentados dizem respeito à escala mundial, não podendo ser feita a correlação direta com Portugal (não podemos dizer linearmente que um terço dos casos em Portugal terão a influência destes nove fatores de risco). 
farmacêuticas e da criação de hábitos que contribuam para construir uma forte rede neuronal, por forma a atrasar o desenvolvimento da doença.

\subsection{A visão da sociedade sobre a doença de Alzheimer e o estigma associado}

No que diz respeito à forma como a DA é concebida pela sociedade, tornou-se relevante compreender se os atores sentiam que existia estigma associado a esta doença, ou não. Para quem lida com a DA, o estigma (construído a partir de preconcepções que "transformamos em expectativas normativas" (Goffman, 1988: 12) ) $^{36}$ ), manifesta-se em duas vertentes: por parte da comunidade local e por parte de profissionais de saúde. Houve concordância, por parte dos entrevistados, de que o estigma perpetuado pela comunidade, mesmo que de forma inconsciente, surge da falta de informação. Seja por tabu, ou pela ausência de preocupação pelo assunto, não há muito interesse em aceder à informação (Silva, 2018: 101103). Por outro lado, a comunidade médica tende a desvalorizar o quadro sintomatológico inicial, perante a analogia entre os sintomas iniciais na $\mathrm{DA}$ e os sintomas que vão surgindo naturalmente devido ao envelhecimento do corpo. Duas cuidadoras familiares entrevistadas (CF1 e CF3) sentiram que os médicos não especialistas na área (médicos de família e/ou médicos destacados nas urgências que não eram de áreas especializadas) desvalorizaram quadros de demência, fazendo um diagnóstico de depressão, o que constituí um problema. Se, por um lado, o diagnóstico desta doença neurodegenerativa é realmente complexo em fases iniciais, por outro lado, um diagnóstico errado pode atrasar o acesso a um tratamento adequado.

As soluções propostas pelos entrevistados apontam para duas linhas de intervenção: por um lado, a elaboração de planos de consciencialização direcionados à comunidade, que elucidem o facto de que deve ser a comunidade a adaptar-se à pessoa com Alzheimer; por outro lado, uma ação direcionada para a comunidade médica. Em concreto, foram suge-

36 Estas são apreendidas e perpetuadas dentro de determinada sociedade e contexto socioecónomico. De acordo com Erving Goffman, o termo de estigma será associado a um atributo profundamente depreciativo, "um atributo que estigmatiza alguém pode confirmar a normalidade de outrem, portanto, ele não é em si mesmo, nem honroso nem desonroso" (Goffman, 1988: 13). 
ridas duas formas de ação: consciencialização para a necessidade de um tratamento e acompanhamento mais focado na pessoa e uma reavaliação do plano curricular de profissionais de saúde (médicos e terapeutas), procurando destacar a necessidade de formar competências empáticas (mais vastas e informadas) que a profissão exige (Silva, 2018: 103).

Outro ponto que se torna fundamental compreender é o atual modelo médico e o impacto que tem na forma como se concebe uma doença neurodegenerativa como a DA. Em 1907, o psiquiatra e neuropatologista Alois Alzheimer descreveu anatomopatologicamente esta doença de estágio final, como «um transtorno degenerativo irreversível diferenciando-se das formas pré-senis (Alzheimer e Pick) das senis (parenquimatosa e arteriosclerótica)» (Sanjuán, 1994: 179). Todavia, ao categorizá-la como «irreversível», o interesse da comunidade médica acaba por se desvanecer, uma vez que o paradigma médico foca-se na cura. Isto é, após o diagnóstico, o doente recebe tratamento maioritariamente sintomatológico. Coloca-se a questão: existe preocupação pelo BE de alguém cuja identidade, capacidade lógica e expressiva se vai desvanecendo?

Os estudos de caso -Alzheimer Portugal e clínica NeuroSer- demonstraram uma metodologia focada no indivíduo, construindo uma linha de tratamento conjugando medicação e técnicas de estimulação cognitiva, que promovem o $\mathrm{BE}$, tendo em conta os gostos do doente, a sua história de vida, e outras informações importantes que a família possa dar. Nesta linha, foi destacada a necessidade de mudança de paradigma do modelo médico ocidental por alguns dos profissionais entrevistados (Silva, 2018: 89-90), que, focado na cura, vê nas doenças crónicas (incuráveis) um obstáculo. Perante esta realidade, importa trabalhar num modelo médico focado na pessoa, na promoção de $\mathrm{QdV}$ e na consciencialização para a importância de continuar a estimular a pessoa (cognitivamente, emocionalmente, etc.).

\section{Bem-estar e uma vida com qualidade}

$\mathrm{Na}$ procura por respostas adequadas, em termos de tratamento/cuidado, o objetivo específico seguinte passou por compreender de que forma é possivel otimizar o $B E$ e $\mathrm{Q} d V$ da pessoa com Alzheimer. Para esse efeito, foram 
consideradas diferentes dimensões de bem-estar: individual (emocional e psicológico ${ }^{37}$ (Ryff e Keyes, 1995); social (relações positivas e respeito mútuo); a questão da participação (conexão entre o $\mathrm{DL}$ e o $\mathrm{FH}$ ) e o BE político (relacional) e, por fim, o BE económico. ${ }^{38}$

$\mathrm{Na}$ área do $\mathrm{BE}$ psicológico, o conceito de florescimento humano tem origem na psicologia positiva, juntando fatores da perspetiva hedónica ${ }^{39}$ (nomeadamente, a relevância das emoções e experiências positivas) e eudaimónica ${ }^{40}$ (a relevância de um bom funcionamento e desenvolvimento do potencial humano), numa tentativa de encontrar a melhor forma de medir o BE do indivíduo. Desta forma, o $\mathrm{FH}$ «representa uma nova conceção de 'vida boa' focada não só em emoções e experiências positivas, mas também em fatores de desenvolvimento do potencial humano e óptimo funcionamento» (Barreiro, 2011: 22). Este é definido como um estado ótimo de saúde mental, no qual o indivíduo sente e funciona positivamente (Ibidem: 22).

Nas áreas do BE social destacam-se o conceito de «capacidade de abordagem» (capability approach) trabalhado por Amartya Sen ${ }^{41}$ e Martha Nussbaum (1993, capacidade do indivíduo/liberdade em determinar um conjunto de valores relacionados com o «ser» e o «fazer», que são por ele aplicados nas escolhas que faz ao longo da vida) e o conceito trabalhado de «bem-estar relacional» (relational wellbeing) ${ }^{42}$ de Sarah White (dinâmica

37 Onde se enquadra o BE emocional e o BE psicológico.

38 De acordo com a pirâmide de Maslow são vários os patamares que devem ser «garantidos» para a pessoa se considerar feliz e plena. O BE social e político (incluindo a participação) são as dimensões mais aprofundados na presente investigação.

39 Daniel Kahneman, considerado o pai da psicologia hedónica, define a perspectiva hedónica como as experiências da vida que são agradáveis ou desagradáveis (Kahneman, Diener e Schwarz, 1999: ix). 40 A perspetiva eudaimónica investiga o potencial humano (Ryan \& Deci 2001; Ryff \& Singer, 2008), partindo da premissa de que a felicidade só pode ser alcançada através da sua realização. Por sua vez, para esta ser obtida será necessária a existência de fatores internos, tais como o sentimento de significado e propósito, por sua vez alcançados através da realização de atividades que permitam ao indivíduo utilizar em pleno as suas capacidades, potencial e talento (Kasdhan et alii, 2008; Ryan \& Deci, 2001).

$4 \mathrm{I}$ have argued for seeing well-being in terms of functioning vectors and the capability to achieve them. The well-being aspect of a person leads to a particular concept of freedom, which has been called well-being freedom (Sen, 1985a: 202-203).

42 «[...] we need to go [...] where people are at present, to explore the social and cultural processes which lie behind these» (McGregor, 2004 In White e Petit, 2004: 88-89). 
entre relações interpessoais e relação com o ambiente envolvente). Ora, se por um lado se torna relevante sentirmo-nos capazes de «ser» e «fazer» o que nos preenche, o que confere sentido/o que nos faz sentir úteis; por outro lado, as relações com o meio e com outras pessoas conferem-nos um sentido de pertença.

Estas dimensões foram correlacionadas com os patamares superiores da pirâmide de Maslow (Paula Moran, 2013) (fazendo a leitura do meio para cima): necessidades sociais (BE relacional), necessidade de autoestima e necessidade de autorrealização (capacidade de abordagem, de ser e fazer). Com o tempo, que vai acentuando a deterioração das capacidades lógicas e físicas, os cuidados com a pessoa focam-se apenas na satisfação das necessidades básicas e na segurança (base da pirâmide). No entanto, é do consenso dos profissionais de saúde entrevistados que se deve tentar cumprir, com o maior critério possível, a satisfação de todos os patamares, atendendo à fase da doença em que cada indivíduo se encontra (Silva, 2018: 109-118). Destacam-se as seguintes aspetos: (a) A base da pirâmide (necessidades fisiológicas e a segurança) devem ser transversais às várias fases, garantindo sempre que estas necessidades são atendidas (em fases mais avançadas, a comunicação está comprometida e, nesse sentido, o cuidador familiar deverá prestar atenção a posicionamentos alterados, demonstrações de desconforto, expressões, sons que demonstrem mal-estar); (b) É muito importante a criação de uma rotina em conjunto com o doente (se ainda for possível) e com a família, por forma a garantir tranquilidade e ausência de sobressaltos, consolidando uma sensação de segurança; (c) O sentimento de «preenchimento» (fulfilment) deve ser sempre valorizado, através do desenvolvimento de atividades (profissionais ou de lazer, enquanto for possível) que tragam este sentimento. Para tal, é fundamental conhecer a história de vida, gostos e rotinas que possam ser adaptadas para esta nova fase de vida; a criação de uma rede social consistente deve ser facilitada (amigos, família), contribuindo para o seu estado de equilíbrio; (d) A sua relação com a comunidade envolvente, com o espaço e o ambiente deve ser incentivada, se a mobilidade ainda for possível (por exemplo, poder passear no bairro, participar em aulas ao ar 
livre, participar em passeios, permitir a máxima liberdade, sem a pessoa sentir que está a ser controlada).

Todos os pontos apresentados, destacam a importância da manutenção do sentimento de utilidade para o BE de cada pessoa - permitir a participação em atividades e tarefas que confiram um sentido de objetivo, sentir pequenas conquistas, criando assim o sentimento de «preenchimento» e de sentido, nomeadamente, sentir que a pessoa pertence à comunidade envolvente/que ainda pode ter um papel ativo na comunidade.

\section{Desenvolvimento local: uma ação a partir de parcerias, participação, territorialização e visão integrada}

Consideremos a definição de $\mathrm{DL}^{43}$ apresentada por Rogério Roque Amaro (2009) no Dicionário Internacional da Outra Economia, onde são propostos dez atributos, a partir dos quais se poderá compreender melhor o conceito: (a) o processo da mudança; (b) centrado numa comunidade territorial de pequena dimensão; (c) que dê resposta a necessidades básicas da comunidade que estão por satisfazer; $(d)$ a partir da mobilização das capacidades locais; (e) a adoção de metodologias participativas e de «empoderamento» (empowerment) da comunidade local; (f) a contribuição de recursos exógenos capazes de mobilizar e potencializar os recursos endógenos; (g) a utilização de uma perspetiva integrada, na abordagem dos problemas e das respostas; $(h$ ) estabelecer parcerias como lógica de trabalho; $(i)$ com impacto tendencial em toda a comunidade; segundo uma grande diversidade de processos, dinâmicas e resultados (Amaro, 2009: 111).

Tomando como ponto de partida a definição e os dez atributos apresentados, são destacadas cinco implicações metodológicas do conceito de DL como dimensões a analisar, tal como sistematizamos seguidamente: participação; visão integrada; trabalho em parceria; territorialização e flexibilidade, tendo sido analisado se eram, ou não, considerados nos estudos de caso apresentados, sendo também apresentados os tipos de resposta que a as organizações analisadas facultam aos seus utentes, os seus limites e potencialidades (apresentado na seção 6.3.).

43 Conceito extremamente debatido na comunidade científica, especialmente pela sua ligação à Revolução Industrial e, portanto, à sua génese economicista. 


\section{Resultados da investigação}

Através da confrontação entre a teoria e os dados empíricos, apresentam-se algumas reflexões finais, procurando discutir a significação atribuída aos resultados analisados ${ }^{44}$. Este processo passa por tentar compreender de que forma os objetivos específicos permitiram validar ou refutar as hipóteses levantadas, através da comparação entre as várias entrevistas (foram realizadas grelhas distintas para poder comparar).

\subsection{Como é concebida a doença de Alzheimer}

Relativamente à conceção da doença em si e da perda que esta causa, os cuidadores familiares escolheram palavras como «sinais», pela constante adaptação às necessidades da pessoa com DA, nomeadamente, a comunicação, que chega a ser feita por sinais; «raiva» e «dor», gerados pelo sentimento de impotência e a dor de todo o processo. Por sua vez, as terapeutas e a diretora da Casa do Alecrim (Fernanda Carrapatoso) optaram por termos como «desestruturação» e "perda de identidade» dos doentes, caraterísticas do processo doloroso pelo qual a pessoa e a família passam. A neuropsicóloga (Margarida Rebolo, Clínica NeuroSer) optou pelo termo de «mudança», sendo esta uma parte inevitável do processo. O neurologista Alexandre Castro Caldas optou por um termo que surgiu em conversa com outro colega de profissão: «Moby Dick». Pela fixação que, enquanto neurologista, sente em resolver o caso de um paciente com Alzheimer - a sua Moby Dick. No decorrer das entrevistas é inteligível o processo psicológico e emocional pelo qual os familiares passam e a necessidade de acompanhamento e cuidado que também deverão ter. $\mathrm{O}$ que se tornou mais claro, com a resposta da psicóloga (Ana M. Cavaleiro, Alzheimer Portugal), que selecionou termos como «angústia», «impotência e desespero», uma vez que é fundamental, quando lidamos com esta realidade, refletir e falar sobre o que esta doença traz a uma família, principalmente, sobre as coisas menos positivas. É importante haver

44 Reflexão sobre as dinâmicas geradas (objeto de estudo) em torno da DA, no contexto português; que potencialidades e limites foram encontrados na ação de cada ator; se emergiram novas problemáticas e, por fim, que cominações existem e que possibilidades poderão ser exploradas. 
uma preparação realista quer da pessoa diagnosticada com DA, quer da família. As mudanças nas dinâmicas relacionais são muitas:

Do ponto de vista da personalidade, da essência da pessoa, da dinâmica da família, da própria forma como ela se posiciona na sociedade... A perspetiva que os membros da sociedade têm em relação aos membros com demência, e àquela pessoa da família, especialmente em diferentes meios culturais em que isso faz muita diferença. Mas sim, acho que isso é uma grande mudança. Por outro lado, é progressiva, não é de um dia para o outro. Se as coisas forem preparadas como deve ser, a família tem tempo para gerir estes processos emocionais associados à mudança. Portanto, tem tempo para preparar a fase seguinte, se for bem acompanhada e aconselhada, obviamente (Margarida Rebolo, neuropsicóloga).

Nos casos analisados, as reações dos filhos que se tornaram nos cuidadores familiares, foi distinta: a cuidadora familiar 1 (CF1) informou-se junto de entidades competentes sobre o assunto, frequentou workshops e começou a pesquisar sobre soluções e formas de apoio, ponderando um apoio domiciliário para quando fosse necessário; o cuidador familiar 2 (CF2) já trabalhava numa instituição social, pelo que acabou por recorrer ao apoio prestado pela mesma, colocando a mãe num lar; por fim, a cuidadora familiar 3 (CF3) deparou-se com uma grande dificuldade em processar as mudanças. Acolheu a mãe em casa, passando a ser cuidadora a tempo inteiro, mas durante muito tempo, preferiu não procurar muita informação, como forma de proteção. As rotinas das filhas e cuidadoras $\mathrm{CF} 1$ e CF3 foram readaptadas. Em ambos os casos, houve tentativa de realizar estimulação cognitiva e motora em casa - seja através de pequenas tarefas em casa (CF3); passeios até a um restaurante de fast-food porque é um mimo que deixa a mãe feliz ou jogar ao loto em casa (CF1). Este processo de adaptação, é descrito pela diretora da Casa do Alecrim como «uma troca de papéis ocupacionais», ou seja, os filhos acabam por se tornar nos pais. No caso do CF2 a institucionalização teve de ser a opção a tomar, uma vez que a sua mãe sempre foi uma mulher de personalidade forte, que nunca aceitou ajuda dos filhos. Após várias tentativas de ajuda serem negadas, a decisão sobre a transferência para o lar teve de ser tomada. 
Concluímos que se torna fundamental (por mais difícil que possa ser) que o cuidador procure a informação adequada, havendo também um investimento por parte das instituições que trabalham o tema da demência, em ações de sensibilização. O processo de aprendizagem deverá ser uma prioridade, podendo passar por dinâmicas como o Café da Memória, um espaço de aprendizagem que contribui para a formação de redes. Torna-se num local de apoio, onde se pode partilhar e conhecer outras pessoas que passam pelo mesmo cenário.

No que diz respeito a uma possível «prevenção» deste inimigo invisível, e considerando que a cura está longe de ser encontrada, por enquanto importa considerar o estudo realizado pela Comissão de Neurologia The Lancet (2017) que apresenta nove fatores de risco evitáveis ${ }^{45}$, sendo, por isso, necessário cuidado na construção de hábitos saudáveis (sobretudo, em tudo o que possa contribuir para o fortalecimento da rede neuronal, através do trabalho da neuroplasticidade). Para tal, no cuidado com a pessoa com doença de Alzheimer é fundamental conhecer a sua história e desenvolver um plano de cuidado através do trabalho de uma equipa multidisciplinar, da família e do cuidador familiar (e, caso ainda tenha essa possibilidade, da pessoa com DA).

O estigma associado a esta doença foi, entre outras palavras, assinalado como silencioso, perante a relutância em aceder a informação sobre a mesma (por medo de lidar com esta realidade, por preconceitos criados pela desinformação, ou até pela desvalorização de alguns sintomas iniciais, o que leva, muitas vezes, a diagnósticos errados - como depressão ou envelhecimento natural, levando assim a um tratamento puramente sintomatológico).

Esta falta de interesse poderá ser observada à luz do que Zygmunt Bauman e Leonidas Donskis (2013) apresentam, na sua teoria, sobre a modernidade líquida, sendo retratada como um dos grandes males da humanidade -a insensibilidade perante o sofrimento humano ${ }^{46}$. A dificuldade em

45 Nove fatores de risco: perda de audição na meia-idade (9\%); não inclusão no ensino médio (8\%); consumo de tabaco (5\%); depressão (4\%); sedentarismo (3\%); isolamento social (2\%); pressão arterial alta (2\%); obesidade (1\%); diabetes tipo $2(2 \%)$. Um terço dos casos poderá ser evitado, se houver cuidado com as rotinas criadas, com os consumos excessivos e com uma vida equilibrada.

46 Querendo com isto dizer que «O mal [...] revela-se com mais frequência quando deixamos de compreender os outros, quando somos invisíveis e evitamos o olhar ético silencioso» (Bauman e Doskis, 
colocar-se no lugar do outro e sentir empatia estabelece-se como a base de diversos problemas na sociedade atual, nomeadamente, do estigma perante pessoas que tenham sido diagnosticadas com DA. Poderá considerar-se que este será um problema identitário, um problema que parte do «eu» (self) $)^{47}$ e que se propaga através da criação de limitações na relação com o «outro». Se Goffman (2014) vê a edificação do ser individual através da performance de diversos papéis, em contextos distintos, para Bauman (2013) essa definição ${ }^{48}$ é alcançada através da ligação com o outro, da escolha de nação, cultura e comunidade. Pois, uma vez que esta ligação é perdida, «a identidade torna-se uma busca de máscaras sem significado» (Bauman, \& Doskis, 2013: 256). Portanto, se o ser humano é um ser social e constrói a sua identidade através da relação com o outro, tornou-se percetível durante a investigação que essa ligação se tem vindo a perder, conduzindo assim à insensibilidade perante uma realidade distante da nossa. A vivência de um indivíduo passa a dar-se através da performance dos seus variados papéis —o pai/a mãe; o/a profissional; o/a filho/a; o/a amigo/a - afastando-se da sua identidade, criada em comunhão com o contexto (desde a sua nação até à sua comunidade local).

Desta forma, a solução poderá estar no regresso ao (desenvolvimento) local. Em contacto com a sua comunidade local, parte da identidade do indivíduo será restituída e a sensibilidade e interesse pelo outro voltará a edificar-se, uma vez que se estará a trazer de volta o sentido de significado e pertença que advém da relação com o outro — «Pois, no fundo, a identidade só adquire significado em virtude de uma ligação com outra pessoa» (Bauman \& Donskis 2013: 256).

2013: 19).

47 «The self consists [...] in an awareness of the multiplicity of roles that are performed in various situated contexts; such performances involve individuals in continually monitoring the impressions they give off to, and make upon, others; public identity is thus performed for an audience, and the private self knows that such performances are essential to identity and to the maintenance of respect and trust in routine social interaction» (Elliot, 2014:37).

48 «[...] quanto mais frágeis se tornarem os nossos poderes de comunidade e a nossa cultura de ligação mais feroz será a busca de identidade. A essência do ser humano não está na autodefinição. Se a nossa sociabilidade for prejudicada e já não tivermos poderes de comunicação, então a identidade torna-se uma busca de máscaras sem significado. Pois, no fundo, a identidade só adquire significado em virtude de uma ligação com outra pessoa. A identidade é um sonho benevolente sobre a nossa semelhança em relação àqueles com os quais nos queremos identificar, assim como sobre as nossas diferenças em relação a eles» (Bauman \& Donskis, 2013: 256). 


\subsection{O florescimento humano como objetivo no desenvolvimento de projetos e ações com pessoas com Alzheimer - o bem-estar e a saúde mental}

Os cuidadores familiares notam um elevado número de pessoas que acabam por se afastar, sendo estes tanto familiares como amigos. Apenas pessoas muito próximas vão mantendo algum contacto. ${ }^{49}$ Perante a postura da comunidade, os cuidadores relatam que, quando saem à rua com as suas mães, notam alguma «alienação» perante a situação. Acreditam que existe uma falta de empatia numa sociedade onde a individualização tem vindo a ganhar terreno ${ }^{50}$. Para além do afastamento dos mais próximos e do distanciamento da sociedade, os cuidadores familiares tendem a isolar-se. Tome-se como exemplo duas cuidadoras entrevistadas, que encaram esta nova realidade como sendo elas as responsáveis pelo cuidado das mães, carregando o peso sozinhas. Os profissionais de saúde reforçam esta teoria, partilhando inúmeros casos de cuidadores que os contactam, ou que chegam às instituições, com sintomas de depressão, ao se isolarem. Todos eles destacaram o quanto é fundamental que o cuidador faça formações, procure informação para estar melhor preparado e, acima de tudo, não descuide do seu próprio cuidado — saúde mental e física. ${ }^{51}$

É muito importante que os cuidadores familiares conheçam a pessoa e o seu historial, procurando também satisfazer as dimensões superiores da pirâmide de Maslow, para o desenvolvimento de rotinas e atividades ${ }^{52}$. Devem ser procuradas as condições propiciadoras de BE, ao permitir es-

49 Importa denotar que não existem reações lineares - a forma como cada pessoa reage é imprevisível, não sendo possível afirmar que «todas as pessoas se afastam». Se, por um lado, há pessoas que têm muita dificuldade em ver um ente querido tão debilitado, e por isso se afastam, há quem se aproxime do cuidador. No entanto, pelo que se pode auferir, o número de pessoas que se afastam é superior.

50 Este afastamento, foi inclusive referido pelos profissionais de saúde. Muitas pessoas acabam por se afastar por terem dificuldade em lidar com esta realidade - a dor avassaladora limita as suas ações.

51 Os cuidadores familiares tendem a colocar o «peso» do cuidado totalmente nas suas costas, isolando-se e desvalorizando a sua própria saúde. Assim sendo, é fundamental que haja um contacto com instituições especializadas neste assunto, podendo facultar formações, apoio, espaços para partilha -como a Alzheimer Portugal ou instituições locais, como o NeuroSer (procurar ferramentas adequadas para proteger o cuidador a nível físico, mental e emocional).

52 Através da consideração dos seus gostos, sonhos e do passado (história ocupacional). 
paço e tempo para a pessoa continuar a desenvolver as suas capacidades, potenciando o seu $\mathrm{FH}$. O trabalho realizado em prol do $\mathrm{FH}$ pretende ajudar o indivíduo a formular uma introspeção relativamente ao que considera ser uma «vida boa», ao estabelecer uma relação com o que o motiva a cada dia. Sugere-se como uma medida importante para o BR, a incorporação deste conceito e das suas premissas nas políticas para o desenvolvimento, de modo a garantir que as comunidades e sociedades tenham acesso a diversas ferramentas, que lhes permitam vidas repletas de significado.

\subsection{Desenvolvimento Local como possível solução}

Antes de partilhar os resultados das dimensões de análise associadas ao DL, é relevante apresentar as formas de resposta que as organizações analisadas disponibilizam aos seus utentes, referindo também os seus limites e potencialidades.

\subsubsection{Estudos de caso de boas práticas em Lisboa-Alzheimer Portugale Clínica NeuroSer}

A Associação Alzheimer Portugal disponibiliza soluções por todo o país (Continente e Madeira), tanto para apoiar no cuidado ao doente de Alzheimer, como para o próprio cuidador familiar, nomeadamente: centros de dia Lar e Centro de Dia "Casa do Alecrim"; linha de apoio; Café da Memória ${ }^{53}$; apoio domiciliários e outros projetos focados na consciencialização ${ }^{54}$. Dinamizam eventos solidários, conferências e workshops, permitindo aos cuidadores investirem na sua formação para melhor lidarem com a situação. É de destacar o exemplo do Café de Memória, local onde foi desenvolvido o trabalho de campo (observação participante). É uma iniciativa/ resposta de base local, com abertura para a participação de pessoas com Alzheimer, e outros tipos de demência, familiares ou cuidadores, e até de pessoas que queiram aprender mais sobre o tema. Realiza-se uma vez por mês em cada local e é desenvolvido por voluntários. Nas duas horas

53 Local onde foi desenvolvido o trabalho de campo - observação participante. É uma iniciativa/ resposta de base local.

54 Em 2015 o número de beneficiários deste tipo de projeto situava-se entre os 15000 e os 16000. 
de cada sessão, procura-se ensinar algo relevante para quem tem de lidar, no dia a dia, com uma pessoa com esta condição (como comunicar, como cuidar, legislação, etc.). Desta forma, é possível aprender mais sobre como lidar com realidade, pode conhecer outras pessoas que passam pelo mesmo e, inclusive, partilhar um pouco da sua própria experiência. Cada mesa tem um voluntário para fazer de mediador e as pessoas são distribuídas aleatoriamente. Existem sempre exercícios de apresentação, a parte do workshop/seminário e no final um momento para chá/café e aperitivos —um momento de descontração e partilha. Como qualquer instituição, a Alzheimer Portugal vê-se limitada pelo financiamento dos projetos. Porém, a sua expansão e alcance, em termos do território português, tem crescido consideravelmente. A aposta em parcerias nacionais e locais apresenta-se como uma potencialidade para a sua ação, tendo sido sugerido por um dos entrevistados, que seria uma mais-valia desenvolver um centro de investigação.

A clínica NeuroSer disponibiliza soluções intermediárias que permitem ao doente permanecer num sítio especializado entre quatro a oito horas. Neste período são realizadas sessões de grupo (estimulação cognitiva e atividades de estimulação em termos sociais e/ou individuais). Uma das atividades que se destacou advém da parceria com a ReFood. Todos os utentes participaram numa «linha de montagem» para preparar refeições para famílias mais carenciadas. Uns liam a receita, outros lavavam alimentos, outros cozinhavam. Esta atividade promove a autonomia e o sentimento de utilidade, de trabalho para um bem comum. Enquanto clínica, os limites da sua ação estão precisamente na capacidade de resposta (em termos quantitativos). Para garantir um cuidado especializado e focado na pessoa só é possível aceitar um número reduzido de pessoas. Há, portanto, limites em termos de financiamento (por ser uma clínica privada) e circunscrição na ação em termos do próprio território. Por outro lado, a sua ação local tem um enorme potencial, uma vez que a comunidade já vai conhecendo o seu trabalho ${ }^{55}$, podendo expandir o seu modelo de ação através da criação de mais parcerias locais.

55 Quando, por exemplo, fazem aulas ao ar livre nos jardins de Telheiras, sendo possível que a comunidade participe também. 
O modelo do Café da Memória, as práticas de promover aulas ao ar livre da Clínica NeuroSer e as atividades em parceria com a Refood, são exemplos de formas de inclusão das pessoas com Alzheimer na sociedade, conferindo um sentimento de «pertença» à sua comunidade e de utilidade.

6.3.2 Dimensões de análise: Territorialização, Flexibilidade; Parcerias; Participação e Visão integrada

A ação da Alzheimer Portugal estende-se a nível nacional (Continente e Madeira), tendo estabelecido diversas parcerias a nível local. Considerando a sua dimensão de ação, há uma dificuldade em garantir soluções totalmente focadas num determinado local, onde haja uma interação direta e trabalhada com a comunidade. No entanto, a iniciativa do Café da Memória consiste num excelente exemplo de iniciativa que considera o território e que se pode adaptar em qualquer ponto do país. Nota-se uma grande preocupação em desenvolver respostas adequadas a cada caso, porém, a instituição, enquanto IPSS, tem os seus limites de alcance. A NeuroSer, por sua vez, tem uma ação local (no município de Telheiras), agindo em conjunto com parceiros locais e com a própria comunidade, como por exemplo, promovendo práticas de desporto ao ar livre, aniversários da clínica e outros eventos abertos à comunidade. A criação de parcerias locais permite um apoio mais otimizado. Tomam-se como exemplo as parcerias criadas pela Alzheimer Portugal ${ }^{56}$ e pela clínica NeuroSer ${ }^{57}$, desenvolvidas para potenciar o alcance da sua ação, criando assim um sentimento de comunidade.

A visão integrada é mencionada pelos profissionais de ambas as instituições, destacada como uma abordagem fundamental que congrega na sua metodologia de trabalho - neurologistas, terapeutas, auxiliares, neuropsicólogos, entre outros que trabalhem diretamente nestas instituições. Porém, em nenhum momento foram mencionados cientistas

56 Lares e centros de dia, equipamentos hospitalares, ajudas técnicas, apoio domiciliário, serviços de higiene, entre outros —informação disponível em: <https://alzheimerportugal.org/pt/text-0-2-104-326-protocolos>.

57 Parcerias: Associação Alzheimer Portugal, serviços sociais da Caixa Geral de Depósitos, parceria informal com a Re-food. 
sociais ou técnicos de intervenção social, nem foi feita qualquer menção sobre a comunidade como um possível ator de intervenção. Nas ações ou procedimentos institucionais, a comunidade é tida como passiva e não como ativa ${ }^{58}$. Não é, por isso, considerada um agente «de ação», integrado nas dinâmicas de intervenção das instituições.

Considerar o envolvimento da comunidade é desafiante: se por um lado temos um consenso sobre a falta de interesse em aceder a informação ou a envolver-se em ações sociais, por outro lado colocam-se as questões: caso exista manifestação de interesse, como poderão lidar com um quadro demencial? Poderão os familiares confiar na interação com desconhecidos? O voluntariado, neste contexto -onde as pessoas com Alzheimer, e outras demências, perdem a capacidade de comunicação- pode ser viável? Ao colocar a questão: «acha que é possível envolver a comunidade no processo de tratamento e prevenção da DA?», os entrevistados respondem positivamente. Tomando em consideração as preocupações levantadas, cuidadores familiares, profissionais de saúde e terapeutas sugeriram algumas precauções/cuidados/ideias para que este envolvimento seja possível: existir predisposição por parte da comunidade e apetência para lidar com pessoas com este quadro clínico; o envolvimento irá depender do projeto e do tipo de objetivos a alcançar. Por exemplo, será possível envolver a comunidade em projetos de sensibilização e divulgação de informação, ou até no cuidado e acompanhamento diário do cuidador familiar e da pessoa com DA, através da facilitação em tarefas do quotidiano, atividades de estimulação cognitiva ou até mesmo para fazer companhia. Para tal, foi sugerido que haja um apoio por parte de instituições, fazendo assim a seleção dos voluntários e dando formação (podendo esta ser certificada), formando sempre equipas de dois. A facilitação/cedência de espaços para atividades pode também ser algo benéfico. Um dos caminhos poderá ser construído através da criação de uma equipa multidisciplinar que trabalhe em conjunto com a comunidade (participando em projetos de intervenção ou sensibilização), por forma a guiar e a monitorizar o seu trabalho.

58 Organizam-se atividades para a comunidade poder fazer parte, como ações de sensibilização ou aulas ao ar livre, sendo enviados convites para a participação nas suas atividades e eventos. 


\subsubsection{Limites e Potencialidades de outros atores envolvidos}

Considerando o papel de outros atores, apresentam-se algumas das potencialidades e alguns dos limites considerados mais relevantes:

(A) Cuidadores familiares. Na ótica dos cuidadores familiares, os limites passam pelo baixo número de soluções adequadas (quantidade de espaços especializados com profissionais formados para lidar com a demência), a falta de divulgação de informação e o facto de terem de manter um trabalho ou cuidar dos filhos enquanto cuidam de alguém com demência. Neste sentido, as potencialidades passam pela formação correta para os profissionais de saúde que lidam com esta realidade, aposta numa maior divulgação sobre os apoios disponíveis e formações para os cuidadores familiares e a criação de um sistema ou uma comissão, a nível nacional, responsável pela inspeção destes locais, garantindo os cuidados adequados e a salvaguarda dos seus direitos. Apesar de os próprios cuidadores familiares não assumirem de forma direta, os profissionais de saúde e terapeutas confirmam que o isolamento é um problema grave, podendo levar ao desenvolvimento de outras doenças e da deterioração da própria saúde mental de quem cuida.

(B) Profissionais de saúde. Na linha do que já foi referido, destaca-se a limitação em termos de ofertas adequadas -lares e centros de dia com lotação, espaços adequados e atividades estimulantes para quem é diagnosticado com demência, assim como, profissionais que cuidem da sua rotina, com formação adequada, garantindo a potencialização do seu FH. Na linha da ação praticada pela clínica Neuro Ser, apresenta-se assim como potencial a criação de mais respostas intermediárias e locais, articuladas com outros atores da comunidade, por forma a garantir uma rede de ação local, garantindo acesso a apoio a toda a comunidade (inclusive aqueles que não têm forma de pagar um cuidado especializado, através de workshops e formações gratuitas para cuidadores - como o Café Memória - onde possa haver partilha de dúvidas e de experiências). É ainda importante destacar, como se afirmou anteriormente, a urgência na otimização da formação dos profissionais de saúde ${ }^{59}$ e um sistema

59 Revisão do plano curricular, que inclua os cuidados a assimilar com o DH (nomeadamente, competências empáticas), a consideração da pessoa e do seu bem-estar, tal como a criação de indicadores 
de fiscalização dos cuidados prestados a pessoas diagnosticadas com Alzheimer, e outras demências.

(C) Estado e Comunidade Médica. Após o desenvolvimento desta investigação, foi criado um estatuto de cuidador ${ }^{60}$ em Portugal, tendo sido um avanço necessário. No entanto, ainda existem áreas em que o Estado pode garantir maior apoio às famílias que convivem com a DA, e outras demências - através da criação de um plano nacional para as demências; revisão e melhoria do estatuto do «cuidador informal»; criação de legislação que dê enfoque à qualidade técnica de quem trabalha com pessoas que tenham tido este diagnóstico; distribuição de recursos e apoios eficazes.

\section{Conclusão - O desenvolvimento local enquanto ponto de partida}

Perante a falta de respostas ${ }^{61}$ (em termos de número e de qualidade, nomeadamente, de profissionais com formação própria para o cuidado de pessoas com Alzheimer, e outros tipos de demência), especialmente para famílias com dificuldades financeiras, apresenta-se como ideia a explorar a criação de um projeto flexível, que tenha como objetivo o desenvolvimento de uma rede social local, contando com a colaboração de diversos atores formais (como centros de dia, polícia, centros de saúde, etc.), incluindo também a comunidade como ator participante e não meramente passivo. A comunidade poderá participar diretamente em projetos de intervenção (dando apoio aos profissionais de saúde) e/ou prevenção que procurem implementar uma visão integrada (em conjunto com as equipas multidisciplinares das instituições e organizações que já trabalhem estas questões). No entanto, não se trata de tentar substituir as funções do Estado, mas sim de encontrar políticas públicas de proximidade efi-

\footnotetext{
de saúde atinentes a estes aspetos por parte das instituições responsáveis (indicadores esses a constar na ficha médica do paciente).

60 Tendo sido aprovado pelo Parlamento, por unanimidade, a 5 de Julho e promulgado pelo Presidente da República a 6 de Agosto, apenas a 6 de Setembro é publicado o Estatuto do Cuidador Informal, anexo à_Lei $\mathrm{n}^{\circ}$ 100/2019. <https://alzheimerportugal.org/pt/news_text-77-1-1055-ja-temos-estatuto-do-cuidador-informal>.

61 A dificuldade em garantir a formação de quem trabalha em lares e centros de dia, de assegurar o acesso a todos aqueles que foram diagnosticados com demência.
} 
cazes. Ao mesmo tempo, o Estado deve desempenhar um papel mais interventivo, particularmente através do apoio às instituições, mediante a criação de legislação (estatutos, apoios a quem seja diagnosticado com esta enfermidade e aos cuidadores familiares e à ampliação da ação da Comissão de Proteção ao Idoso ${ }^{62}$ ) que proteja as pessoas com Alzheimer (e outras demências) e cuidadores familiares, potenciando a expansão da ação de associações como a Alzheimer Portugal, bem como a criação de oportunidades que permitam o desenvolvimento de espaços para as iniciativas promovidas por este tipo de organizações locais.

\section{Bibliografia}

Alzheimer Europe, 2019. Dementia in Europe Yearbook 2019. Estimating the prevalence of dementia in Europe. European Union's Health Programme (2014-2020).

Alzheimer Portugal, 2017a. «Prevalência da Demência». Alzheimer Portugal. Adaptado Alzheimer Europe. [online] Disponível em: <http://alzheimerportugal.org/pt/prevalencia>; [Acedido em: 10 de Setembro 2017]. (Alzheimer Europe, 2019: 12)

Alzheimer Portugal, 2017b. «Snoezelen». Alzheimer Portugal. Adaptado de Alzheimer Austrália [online] Disponível em: <http://alzheimerportugal.org/pt/text-0-10-46-57-snoezelen> [Acedido em 10 de setembro de 2017].

Alzheimer Portugal, 2017c. «Café da Memória». Alzheimer Portugal. [Online] Disponível em: <http://alzheimerportugal.org/pt/text-0-10-97-274-cafe-memoria> [Acedido em 4 de setembro de 2017]. Alzheimer Portugal, 2017d. «Protocolos». Alzheimer Portugal. [Online] Disponível em: <http://alzheimerportugal.org/pt/protocolos>. [Acedido a: O1 de outubro de 2017].

62 A Associação Regional do Norte criou uma Comissão de Proteção ao Idoso: "uma organização da sociedade civil, de âmbito regional, que surge em Dezembro de 2013, da reflexão de um grupo de fundadores de várias áreas socioprofissionais, com sensibilidades diversas, que identifica e aceita que os idosos, maioritariamente, constituem um grupo especialmente vulnerável e que, por isso, merecem que lhes seja dirigida uma maior proteção, por parte dos poderes públicos e da sociedade em geral (entrevista a Carlos Branco, 2016 em Revistaspot). Porém, importa referir que a sua ação é sempre passível de discussão e análise. Se, por um lado, a Comissão de proteção de crianças se protege menores, aqui estamos a falar de adultos. Onde está o limite que nos permita decidir por outras pessoas? 
Alzheimer Portugal, 2017e. «Apoios e Serviços». Alzheimer Portugal. [Online] Disponível em: <http://alzheimerportugal.org/pt/apoios-e-servicos> [Acedido a: 01 de outubro de 2017].

Alzheimer Portugal, 2019. «Já temos estatuto do cuidador informal?». Disponível em:<https://alzheimerportugal.org/pt/news_text-77-1-1055-ja-temos-estatuto-do-cuidador-informal> [Acedido a :10.09.2019]

Amaro, Rogério, 2009. «Desenvolvimento Local». In Cattani, Antonio D.; Laville, Jean-Louis; Gaicer, Luiz I.; Hespanha, Pedro Dicionário Internacional de Outra Economia. Coimbra: Edições Almedina, pp 108 - 112.

Barreiro, Patrícia, 2011. Florescimento Humano e Empowerment: Da relação entre os conceitos e seus contributos para as novas perspetivas do Desenvolvimento. Mestrado Lisboa. ISCTE-Instituto Universitário de Lisboa.

Bauman, Zygmunt e Doskis, Leonidas, 2013. Cegueira Moral. A Perda da Sensibilidade na Modernidade Líquida. Rio de Janeiro: Zahar, 2014.

BELSKY, Janet, 1999. The psychology of aging: theory, research, and interventions. Pacific Grove: Brooks-Cole Publishing, pp.194-224.

Burgess, Robert G., 1997. A pesquisa de terreno. Uma introdução. Oeiras: Celta Editora. pp. 111-133.

Goffman, E. 1961. «Asylums». In. ElLiot, Anthony 2014. Contemporary Social Theory-An Introduction. NY: Anchor Books.

Goffman, Erving. 1988. Estigma: Notas sobre a Manipulação da Identidade Deteriorada, Rio de Janeiro, Editora LTC, 1988.

Guerra, Isabel, 2006. Pesquisa Qualitativa e Análise de Conteúdo. Sentidos e formas de uso. Cascais: Principia.

Henriques, José Manuel, 2007. Globalização, 'desintegração local' e governança: discursos e possibilidades. In SAlavisa, Isabel; Rodrigues, Walter; MenDONÇA, Sandro. (org.), 2007. Inovação e Globalização: Estratégias para o desenvolvimento económico territorial. Porto: Campo das Letras.

INE (Instituto Nacional de Estatística), 2017. Mantém-se o agravamento do envelhecimento demográfico, em Portugal, que só tenderá a estabilizar daqui a cerca de 40 anos. Última atualização: 29 de março de 2017 [online] Disponível em: <https:/www.ine.pt/xportal/xmain?xpid=INE\&xpgid=ine_destaques\&DESTAQUESdest_boui=277695619\&DESTAQUESmodo $=2 \& x$ lang $=$ pt $>$ [Acedido a 28 de setembro 2020]. 
INE (Instituto Nacional De Estatística), 2019. Redução da população residente em 2018 menor que a de 2017 - 2018. Última atualização: 14 de julho de 2019 [online] Disponível em: <https://www.ine.pt/xportal/xmain?xpi$\mathrm{d}=$ INE\&xpgid=ine_destaques\&DESTAQUESdest_boui=354227526\&DESTAQUESmodo=2\&xlang=pt $>$ [Acedido a 28 de setembro 2020].

Instituto de Segurança Social, I.P., 2005. Situação Social dos Doentes de ALZHEIMER um estudo exploratório. Fundação Montepio Geral. [online] Disponível em: <http://www.seg-social.pt/documents/10152/135898/ situacao_social_doentes_alzeimer/ba9oaeb2-eb23-4168-9ce6-05e13aaicf2 $\mathrm{f}>$ [Acedido a 28 de setembro 2020]

Kahneman, D., Diener, E. e Schwarz, N., 1999. Well-being: The foundations of hedonic psychology. New York, NY US: Russell Sage Foundation, pp. 3-24.

KEYES, C., 2007. «Promoting and protecting mental health as flourishing: A complementary strategy for improving national mental health». American Psychologist. Volume 62 (2), pp. 95-108. Disponível em: <https://www.researchgate.net/publication/6482455_Promoting_and_ Protecting_Mental_Health_as_Flourishing_A_Complementary_Strategy_for_Improving_National_Mental_Health> [Acedido em 30 de Agosto 2016].

Moran, Paula, 2013. Pirâmide de Maslow. [online] Disponível em: <http:// www.mood.com.br/piramide-de-maslow/>. Acedido em: [Acedido em 5 de outubro de 2017].

NeuroSer, 2015. «Áreas de intervenção.» [online] Disponível em: <http:// NeuroSer.pt/areas-de-intervencao/> [Acedido a 10 de outubro de 2017].

Nussbaum, Martha \& Sen, Amartya (ed.), 1993. The Quality of Life. Oxford: Clarendon Press, pp. $30-50$.

Neves, Rui, 2019. «Negócio dos lares para idosos já vale mais de 300 milhões em Portugal». Jornal de Negócios. Junho de 2014. Disponível em: $<$ https://www.jornaldenegocios.pt/economia/detalhe/negocio-dos-lares-para-idosos-ja-vale-mais-de-300-milhoes-em-portugal Acedido em: [Acedido em 28 de setembro de 2020]. 
Pinho, Liliana, 2008. Demência - A marcha diagnóstica no âmbito dos Cuidados de Saúde Primários. Mestrado. Faculdade de Ciências da Saúde - Universidade da Beira Interior.

Quivy e Campenhoudt, 1995. Manual de Investigação em Ciências Sociais. Lisboa. Gradiva.

Revistaspot, 2016. Comissão de Proteção ao idoso: pela defesa dos direitos sociais e da dignidade humana. Entrevista a Carlos Branco [online] Disponível em: <http://revistaspot.pt/index.php/2016/10/12/comissao-de-protecao-ao-idoso-pela-defesa-dos-direitos-sociais-e-da-dignidade-humana/>. [Acedido a: 10 de outubro de 2017]

Ryan, R. e DeCI, E., 2001.« On Happiness and Human Potentials: A review of Research on Hedonic and Eudaimonic Well-Being». Annual Review of Psychology. Volume 52, pp. 141-166.

Ryff, C. e Keyes, C., 1995. «The Structure of Psychological Well-Being Revisited». Journal of Personality and Social Psychology. Volume 69 (4), pp. 719-727.

RyfF \& Singer, 2008. Know Thyself and Become What You Are: A Eudaimonic Approach to Psychological Well-Being. in Journal of Happiness Studies 9(1):13-39 . February 2008. Disponível em: <https://www. researchgate.net/publication/23545616_Know_Thyself_and_Become_ What_You_Are_A_Eudaimonic_Approach_to_Psychological_WellBeing>. Acedido em: [7 de abril de 2016].

SAnjuán, Júlio, 1994. Demência, In GutiérRez, J.L. (org.), 1994. Dez palavras-chave em psiquiatria. Petrópolis, Vozes. Pp.177-201.

Sen, Amartya, 1985. Commodities and Capabilities. Amsterdam: ElsevierNorth Holand Publishing Co.

Silva, Joana Carrilho, 2018. Desenvolvimento Local na promoção de Bem-Estar $e$ Qualidade de Vida na Doença de Alzheimer. Mestrado. ISCTE - Instituto Universitário de Lisboa.

White, Sarah \& Pettit, Jethro, 2004. Participatory Methods and the measurement of well-being. pp. 88-96. [online] Disponível em: <http:// www.welldev.org.uk/research/workingpaperpdf/wedo8.pdf> [Acedido a: 7 de outubro de 2016].

WHO, 2017. Dementia. [online] Disponível em: <http://www.who.int/mediacentre/factsheets/fs362/en/> [Acedido em: 20 de junho de 2017]. 